\title{
Transplanted Dental Pulp Stem Cells Migrate to Injured Area and Express Neural Markers in a Rat Model of Cerebral Ischemia
}

\author{
Xuemei Zhanga Yinglian Zhou ${ }^{a}$ Hulun Lib Rui Wanga Dan Yang ${ }^{a}$ Bing Lia \\ Xiaofang $\mathrm{Cao}^{c}$ Jin $\mathrm{Fu}^{\mathrm{a}}$ \\ aDepartment of Neurology, The Second Affiliated Hospital of Harbin Medical University, Harbin, \\ bDepartment of Neurobiology, Neurobiology Key Laboratory, Harbin Medical University, Harbin, \\ 'Department of Dentistry, The Second Affiliated Hospital of Harbin Medical University, Harbin, China
}

\section{Key Words}

Focal cerebral ischemia - Dental pulp stem cells • Cell transplantation

\begin{abstract}
Background/Aims: Ischemic stroke is a major cause of disability and mortality worldwide, while effective restorative treatments are limited at present. Stem cell transplantation holds therapeutic potential for ischemic vascular diseases and may provide an opportunity for neural regeneration. Dental pulp stem cells (DPSCs) origin from neural crest and have neuro-ectodermal features including proliferation and multilineage differentiation potentials. Methods: The rat model of middle cerebral artery occlusion (MCAO) was used to evaluate whether intravenous administration of DPSCs can reduce infarct size and to estimate the migration and trans-differentiation into neuron-like cells in focal cerebral ischemia models. Brain tissues were collected at 4 weeks following cell transplantation and analyzed with immunofluorescence, immunohistochemistry and real-time polymerase chain reaction (RTPCR) methods. Results: Intravenously administration of rat-derived DPSCs were found to migrate into the boundary of ischemic areas and expressed neural specific markers, reducing infarct volume and cerebral edema. Conclusions: These results suggest that DPSCs treatment may serve as a potential therapy for clinical stroke patients in the future.
\end{abstract}

(C) 2018 The Author(s)

Published by S. Karger AG, Basel

\section{Introduction}

Ischemic stroke resulting from abrupt interruption of cerebral blood flow represents one of the major causes of disability and mortality worldwide [1]. The central nervous system has limited neuronal regenerative potential in response to stroke. Exploring reparative

$X$. Zhang and Y. Zhou contributed equally to this work. 


\section{Cellular Physiology Cell Physiol Biochem 2018;45:258-266 \\ \begin{tabular}{l|l} 
DOI: 10.1159/000486772 22,2018 & $\begin{array}{l}\text { O 2018 The Author(s). Published by S. Karger AG, Basel } \\
\text { www.karger.com/cpb }\end{array}$
\end{tabular} \\ Zhang et al.: Dental Pulp Stem Cells Express Neural Markers in Cerebral Ischemia Model}

approaches is a promising field of investigation. Stem cell transplantation provides an alternative strategy for replacing the lost neurons and repairing the damaged tissues. Dental pulp stem cells (DPSCs) are originated from cranial neural crest, have neuro-ectodermal features with stronger proliferation, and exhibit neurogenic, odontogenic, chondrogenic, adipogenic and myogenic differentiation abilities after long term cryopreservation [2-4]. DPSCs have received much attention in the field of regenerative medicine because of their easy isolation, expansion and storage [5]. Since these cells are applicable for autologous tissue regeneration and cell-transplantation therapies without the risk of an alloimmunization reaction, less ethical issues are involved in their clinical application. For potential use in neurological conditions, DPSCs can secrete neurotrophic factors with neuroprotective effect, enhancing neurogenesis and angiogenesis [6-8]. Adult human DPSCs may promote blood-brain barrier permeability via expressing vascular endothelial growth factor, also supporting their use in therapy for neurological disorders [9]. In fact, it is suggested that DPSCs may offer therapeutic potentials for neurodegenerative diseases [10], cranial nerve injury $[11,12]$, spinal cord injury, cerebral ischemia and so on. In this study, we evaluated whether intravenous administration of DPSCs can reduce infarct size and estimated the migration and trans-differentiation of transplanted DPSCs into neuron-like cells in a rat model of focal cerebral ischemia.

\section{Materials and Methods}

\section{Animals}

Pathogen free Male Sprague-Dawley (SD) rats weighing 240-250 g were purchased from the animal center of the second affiliated hospital of Harbin Medical University. The experimental procedures and study design were conducted according to institutional guides for animal experiments approved by the Institutional Animal Care and Use Committees of Harbin Medical University.

\section{Experiment design}

Rats were randomly allocated into two groups after middle cerebral artery occlusion (MCAO), i.e., saline group received saline injection 24h after MCAO (n=12) and DPSCs group subjected to DPSCs transplantation $24 \mathrm{~h}$ after MCAO ( $\mathrm{n}=12)$. A subset of animals ( $\mathrm{n}=4$ /group) were allowed to survive for 1 week following MCAO to assess the establishment of the ischemic model. Other animals were allowed to survive 4 weeks after MCAO, with halves of animals subjected to histological ( $n=4$ /group) and biochemical (i.e., RT-PCR, n=4/ group) studies, respectively. The 4 week surviving point was chosen considering that this time would allow the transplanted cells to home and possibly integrate in the brain and exhibit putative protective impact on stroke recovery. In addition, pilot study was carried out to familiarize with and establish the model of MCAO, with animals $(\mathrm{n}=10)$ sacrificed $24 \mathrm{~h}$ after MCAO occlusion and brains stained with triphenyltetrazolium chloride (TTC) to visualize the infarct areas.

\section{Isolation, culture, labeling and transplantation of rat derived DPSCs}

Dental pulp was harvested from the incisors of 4-week-old male SD rats and was digested with $0.3 \%$ collagenase in phosphate-buffered saline. The cells were placed into $75 \mathrm{~cm}^{2}$ plastic flask and then cultivated in $12 \mathrm{ml}$ of alpha modification of the Eagle's medium ( $\alpha$-MEM), including $10 \%$ fetal bovine serum, 1\% penicillin $(100 \mathrm{U} / \mathrm{ml})$ and streptomycin $(100 \mathrm{mg} / \mathrm{ml})$, at $37^{\circ} \mathrm{C}$ in humidified atmosphere with $5 \% \mathrm{CO}$. After 72 hours, new culture medium was added and the non-adherent cells were removed. When adherent cells grew to $80 \%$ confluency, cells were incubated with $0.25 \%$ trypsin and $1 \mathrm{mM}$ ethylenediaminetetraacetic acid at $37^{\circ} \mathrm{C}$ for 2 minutes. The above prepared passage 3 DPSCs were used for this experiment. To identify and monitor the transplanted cells in the injured regions, noninvasive green fluorescent dye PKH 67 labeling was used. A total of $1 \times 10^{6}$ cells DPSCs in $0.5 \mathrm{ml}$ saline was injected into the MCAO rats via tail vein $24 \mathrm{~h}$ after the induction of stroke, i.e., a subacute phase of stroke. Equal amount of saline was injected into control rats. All of these procedures were conducted under aseptic protocols. The following measurements were performed four weeks after the DPSCs transplantation or saline injection. 


\section{Cellular Physiology Cell Physiol Biochem 2018;45:258-266 \begin{tabular}{l|l|l} 
DOI: 10.1159/000486772 & and Biochemistry 2018 The Author(s). Published by S. Karger AG, Basel \\
wuww.karger.com/cpb
\end{tabular}

Zhang et al.: Dental Pulp Stem Cells Express Neural Markers in Cerebral Ischemia Model

\section{Induction of focal cerebral ischemia}

Focal cerebral ischemia was established through the occlusion of middle cerebral artery (MCAO). Animals were anesthetized by intraperitoneal injection of $10 \%$ chloral hydrate (3.5 ml/100 g). Body temperature was maintained at $(37 \pm 0.5){ }^{\circ} \mathrm{C}$ by using heating lamps during the surgery. A ventral midline incision in the neck was made to expose and isolate the right internal carotid artery (ICA), external carotid artery (ECA) and common carotid artery (CCA) bluntly. The CCA was ligated close to its origin with a 4-0 silk suture, then a 4.0 monofilament nylon suture with a rounded silicone wrapped tip was inserted into the right ICA, and advanced 18-20 mm into the origin of right middle cerebral artery (MCA) until a slight resistance was felt. After $120 \mathrm{~min}$ of the occlusion of the right MCA, the 4.0 monofilament nylon suture was removed to allow reperfusion. The sham group received the same procedure except for the occlusion of the right MCA. When the procedures were finished, the incision was sutured and the animals returned to their cages. The induction of brain ischemia via neck dissection and vessel ligation could avoid a major concern for regenerative therapies for CNS diseases caused by intracranial surgery or disruption of the blood brain barrier.

\section{TTC staining}

Triphenyltetrazolium chloride (TTC) stain was used to visualize the infarct volume as described previously [13]. At $24 \mathrm{~h}$ after reperfusion, the brains were rapidly removed on ice, frozen at $-20^{\circ} \mathrm{C}$ for $25 \mathrm{~min}$ and cut into five consecutive coronal slices, which were incubated in 1\% TTC in $0.1 \mathrm{M}$ sodium phosphate buffered saline (PBS, pH 7.4) at $37{ }^{\circ} \mathrm{C}$ for $25 \mathrm{~min}$. In the slices red area represented normal brain tissue and pale area was infarct tissue. All brain slices were photographed with a digital camera, with the total infarct zone ratio for each brain calculated as follows: (left hemisphere area-right non-infarcted area)/ (left hemisphere area*2) [14].

\section{HE staining}

Animals were perfused transcardially with $0.9 \%$ saline followed by $4 \%$ paraformaldehyde. The brains were cut into frontal slices and then embedded with paraffin. Paraffin sections were treated with xylene, 100\% ethanol for 5 minutes twice, and 95\%, 90\%, and $80 \%$ ethanol each for 3 minutes, stained with hematoxylin for 10-15 minutes, and washed with tap water for 10 minutes. After this, $1 \%$ hydrochloric acid alcohol was added for 1 second to visualize the blue color, washed with tap water for 10 minutes and further stained with eosin for 5 minutes. HE stained sections were dehydrated with $80 \%$, 95\%, and 100\% graded ethanol for 1 minute twice, cleaned with xylene and coverslippered with neutral gum before light microscope examination.

\section{Immunofluorescence}

Rats were anaesthetized with intraperitoneal injection of $10 \%$ chloral hydrate and then perfused transcardially with $0.9 \% \mathrm{NaCl}$ at $4^{\circ} \mathrm{C}$ and followed by $4 \%$ paraformaldehyde in PBS (pH 7.4). The brains were removed, kept in $4 \%$ paraformaldehyde at $4^{\circ} \mathrm{C}$ overnight and then immersed in $20 \%$ and $30 \%$ phosphatebuffered sucrose at $4^{\circ} \mathrm{C}$ until sinking into the bottom. The brains were cut into 35 micron thick frontal sections in a cryostat. After blocking with PBS containing 5\% normal goat serum, the frozen sections were incubated with primary antibodies including rabbit anti- $\beta$ III tubulin, rabbit anti-doublecortin (DCX), mouse anti-nestin and mouse anti-neurofilament $\mathrm{H}(\mathrm{NF}-\mathrm{H})$ overnight at $4^{\circ} \mathrm{C}$. The sections were washed three times with $0.1 \mathrm{M}$ PBS, 5 min each time and incubated with rhodamine conjugated anti-rabbit/mouse IgG/IgM (1:400) for $1.5 \mathrm{~h}$ at room temperature. The nuclei were stained with 4 '-6-diamidino-2-phenylindole (DAPI). Co-localization of PKH 67, neural specific markers and DAPI was conducted by laser scanning confocal microscopy at wavelengths of Alexa Fluor 594 nm (red), Alexa Fluor 488 nm (green) and Alexa Fluor 405nm (blue).

\section{Immunohistochemistry}

The rats were deeply anaesthetized at four weeks after cell transplantation by an overdose of $10 \%$ chloral hydrate. The rat brains were fixed by transcardiac perfusion with saline, followed by perfusion and immersion in 4\% paraformaldehyde in 0.1 M PBS solution ( $\mathrm{pH} 7.4$ ). The sections were then rinsed with Tris buffer and treated with $0.3 \% \mathrm{H} 2 \mathrm{O} 2$ to block endogenous peroxidase. Following this, the sections were blocked with $10 \%$ normal goat serum and $0.1 \%$ Triton X-100 in PBS for 30 minutes at room temperature, 


\section{Cellular Physiology \begin{tabular}{l|l|l} 
and Biochemistry $10.1159 / 000486772$ & $\begin{array}{l}\text { D 2 2018 The Author(s). Published by S. Karger AG, Basel } \\
\text { www.karger.com/cpb }\end{array}$
\end{tabular}}

Zhang et al.: Dental Pulp Stem Cells Express Neural Markers in Cerebral Ischemia Model

incubated with rabbit anti- $\beta$ III tubulin, rabbit anti-doublecortin (DCX), mouse anti-Nestin, mouse antineurofilament $\mathrm{H}(\mathrm{NF}-\mathrm{H})$ overnight at $4^{\circ} \mathrm{C}$, with goat anti-mouse or anti-rabbit IgG (1:500) for 1 hour and with an avidin-biotin-peroxidase complex (Vectastain ABC kit) for 1 hour at room temperature. After brief washing in PBS, sections were counterstained with hematoxylin, dehydrated, mounted, then observed and analyzed under a bright-field microscope to determine the number of positive cells in the brain tissues.

\section{RT-PCR analysis}

RNA was harvested from ischemic brains by using Trizol reagent and reverse transcription was conducted according to conventional protocols. All the primer sequences of neural specific markers were confirmed by established GenBank sequences. The primers were used to amplify the duplicate PCRs, while $\beta$-actin was used as a control. Each sample was analyzed in triplicate. Cycling procedures included preincubation at $95^{\circ} \mathrm{C}$ for 15 seconds, annealing and extension at $57^{\circ} \mathrm{C}$ for 60 seconds, followed by $95^{\circ} \mathrm{C}$ for 15 seconds and finally cooling at $4^{\circ} \mathrm{C}$ for 5 minutes.

\section{Statistical analysis}

Data were expressed as the mean \pm Standard deviation (SD). $P<0.05$ was considered statistically significant. All statistical analyses were performed with Graph Pad prism5.0.

\section{Results}

\section{Characterization of DPSCs}

The DPSCs started to form colonies in 4-5 days and attached to the plate surfaces. DPSCs displayed ramified, triangular, oval and typical fibroblast-like cell morphology and showed high proliferative capacity (Fig. 1). Around 7 days, adherent DPSCs reached full confluency.

\section{Focal cerebral ischemia animal model}

TTC and HE staining were used to analyze and verify the focal cerebral ischemia model. White zone in brain tissues represented infarct areas caused by ischemic injury, and red zone represented normal brain tissues (Fig. 2). Brain infarcts of right hemisphere were induced by the occlusion of middle cerebral artery during the acute phase. Rats in sham group displayed red staining, suggesting no ischemic damage. $\mathrm{HE}$ staining showed remarkable decrease of neurons in the ischemic brains. Neuronal arrangement was irregular with vacuoles, eosinophilic cytoplasm and increased gap formation between cells. Inflammatory cells infiltration was detected.

\section{DPSCs reduced cerebral} infarct volume

To investigate whether intravenously transplanted DPSCs could decrease infarct volume and cerebral edema in cerebral ischemic models, TTC staining was conducted

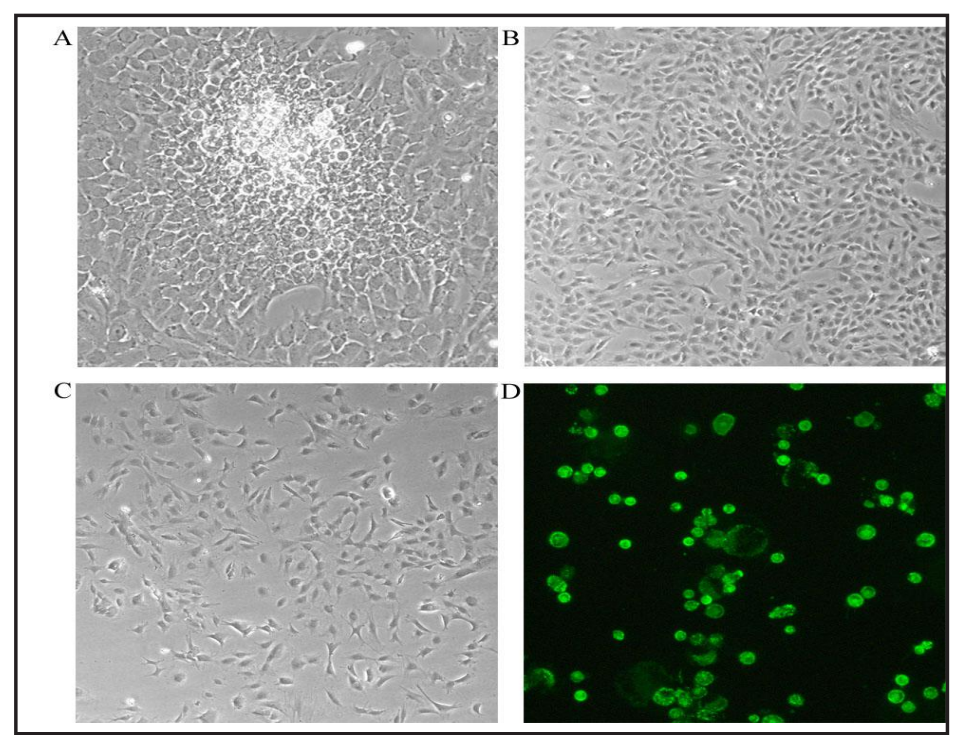

Fig. 1. Morphology of dental pulp stem cells in culture. A: P0: DPSCs start to form colonies 4-5 days in vitro and attach to the plate surfaces. $\mathrm{B} \sim \mathrm{C}$ : P2 P3: DPSCs display ramified, triangular, oval and typical fibroblast-like cell morphology. D: PKH67 labeled DPSCs emit green fluorescence under fluorescence microscope. 


\section{Cellular Physiology and Biochemistry}

to measure infarct volume and brain edema at 1 week after cell transplantation. Data showed that cerebral infarct volume was about $30.20 \pm 2.14 \%$ in saline group, whereas the white zone was about $20.85 \pm 1.86 \%$ in DPSCs group ( $p<0.05$ ) (Fig. 3). Therefore, brain edema and neuronal damage was also significantly relieved in DPSCs group compared with saline group.

\section{DPSCs migrate into} ischemic areas

The spatial distribution of DPSCs was observed and analyzed following transplantation into the cerebral ischemic models. The grafted green fluorescent dye pre-labeled cells could easily be identified under fluorescent microscope at higher magnification, while the signal could not yield sufficient cellular resolution at low magnification (data not shown). Compared with the saline group, we detected transplanted cells that were colocalized with cell tracker PKH 67, neural specific markers and DAPI under laser scanning confocal microscopy in DPSCs group. PKH 67 have low cytotoxicity and emit green fluorescent signal in vivo. PKH 67 positive cells expressed neural specific markers $\beta$ III tubulin, DCX, Nestin, NF-

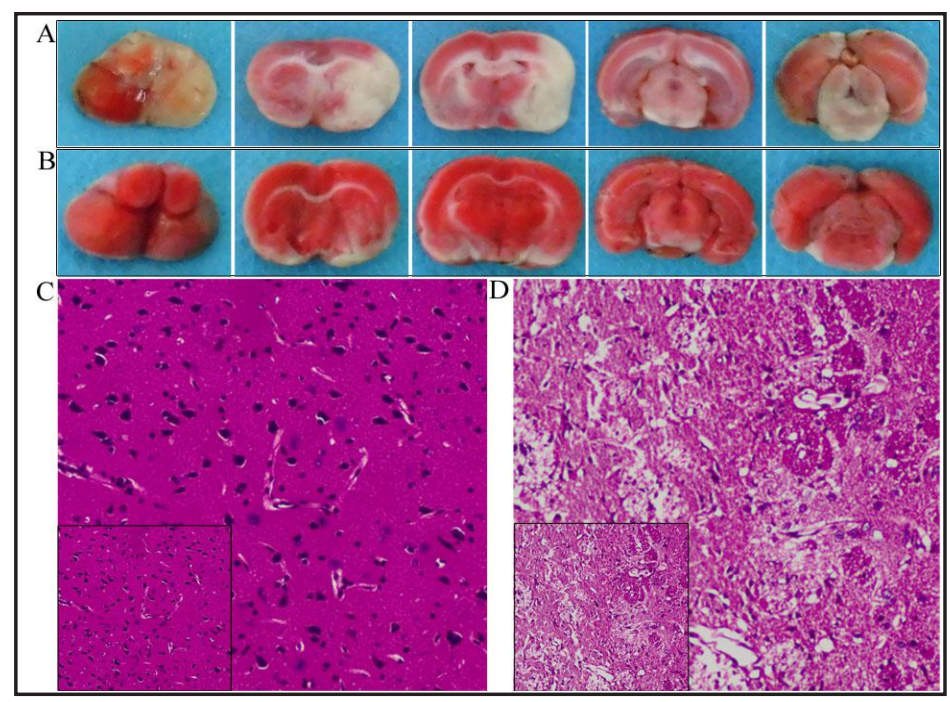

Fig. 2. Histopathological features of brain tissue $24 \mathrm{~h}$ after the occlusion of middle cerebral artery. A: TTC staining of brain slices from MCAO models. B: TTC staining of brain slices from the sham group. The red color represents normal tissue and pale areas are infarct regions. C: HE staining of animals in sham group represents normal histology in brain. D: HE staining of MCAO models indicates remarkable decrease of neuronal profiles. The infarct area contains irregular vacuoles, eosinophilic cytoplasm and increased gap formation around the cells.

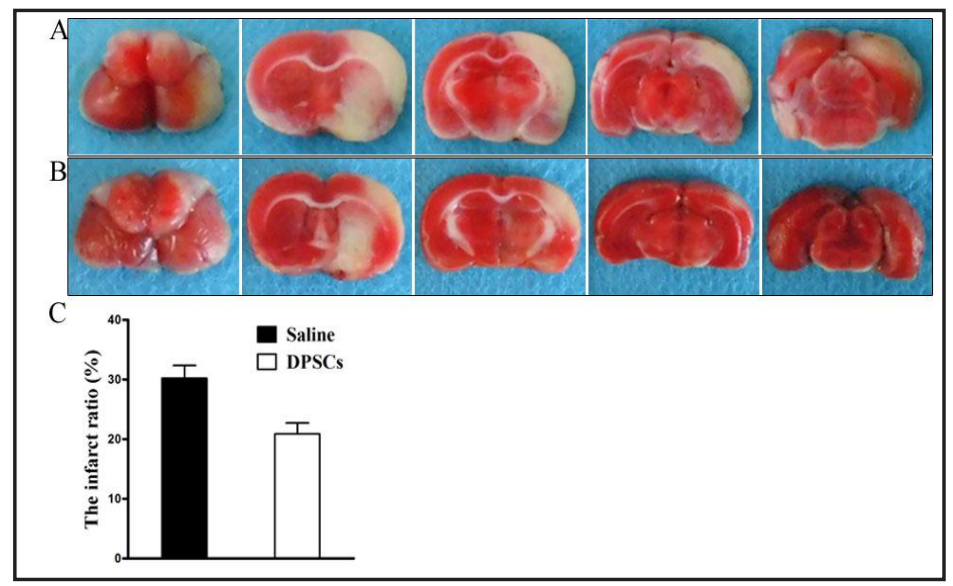

Fig. 3. Infarct volume was analyzed and brain edema were measured with TTC staining at one week after cell transplantation. Saline group exhibited that cerebral infarct volume was about $30.20 \pm 2.14 \%$, whereas the DPSCs decreased the white zone to $20.85 \pm 1.86 \%(\mathrm{p}<0.05)$.

$\mathrm{H}$, which showed cytoplasm in yellow and DAPI-stained nuclei in blue (Fig. 4). The cells were almost gathered in the boundary of ischemia brain tissues, and were not detectable in the contralateral hemisphere.

\section{Grafted DPSCs express neural specific markers}

Immunolabeling for neural specific markers were used to detect the differentiation activity of DPSCs in the ischemic models. $\beta$ III tubulin, an early neuronal marker, is a constituent of neuronal microtubules and plays an important role in axon growth and in the development 
of normal brain $[15,16]$. DCX, a specific marker of immature neurons [17], is a valuable alternative marker used to measure the levels of neurogenesis [18]. Nestin, an intermediate filament protein, is expressed in dividing cells during the early stages of development in the central nervous system, peripheral nervous system and in myogenic and other tissues [19]. NF-H is a marker of mature neurons. I $m$ mun of lu ore scence data suggested that grafted DPSCs express neural specific markers. Immunohis to che mistry data illustrated that DPSCs group had more positive signals for neural specific markers compared with saline group (Fig. 5). Moreover, RT-PCR suggested that the gene expression of neural specific markers was up-regulated in DPSCs group relative to saline group (Fig. 6).

\section{Discussion}

In this study, rat incisors derived DPSCs were successfully isolated and cultured. Transplanted DPSCs exhibited neuroprotective effect on brain ischemia rats, by reducing the infarct volume and enhancing the neurological function recovery after cerebral ischemic injury. The results of the present study suggest that transplanted DPSCs can survive, proliferate and migrate into and locate around the ischemic areas in a model of MCAO. DPSCs provide a novel platform for ischemic stroke treatment with the most appealing potentials. DPSCs have advantages of less invasive isolation from autologous dental pulp, superior proliferation and inherent propensity to differentiate into neural cells. Intravenous infusion is the gold standard delivery method in the administration of stem cells with the least damage compared with other administration routes such us

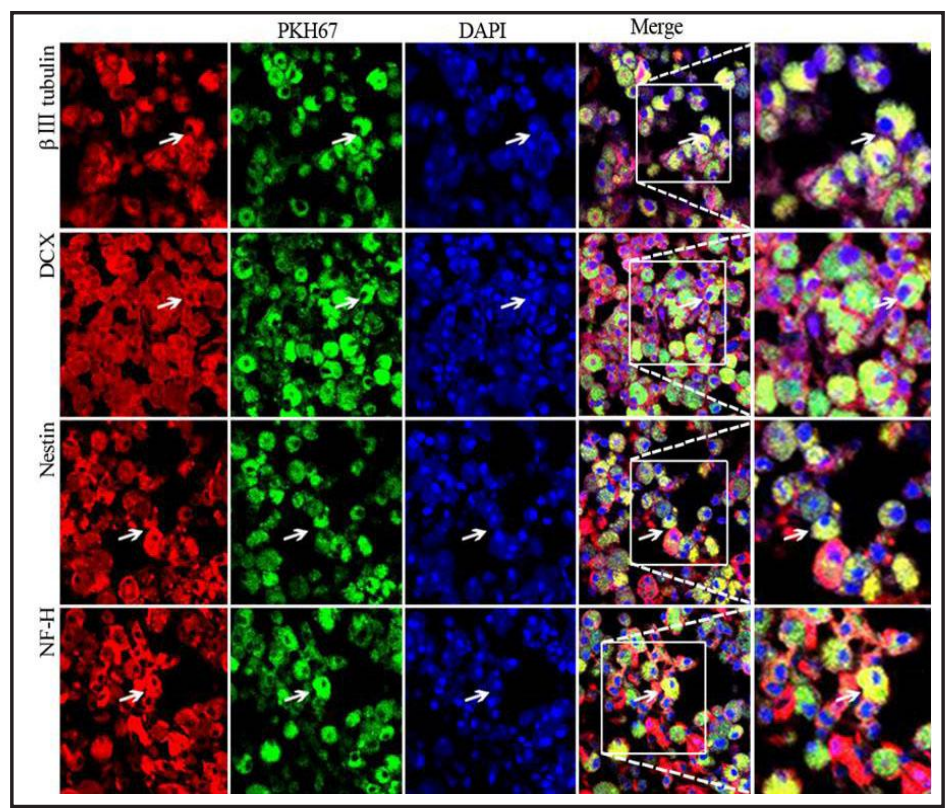

Fig. 4. Green fluorescence represent PKH 67, red fluorescence represent neural specific markers $\beta$ III tubulin, DCX, Nestin and NF-H, blue fluorescence represent DAPI. PKH 67 positive cells express neural specific markers, which show cytoplasm in yellow and DAPI-stained nuclei in blue. The cells are almost gathered in the boundary of ischemic brain tissues, which are not detectable in the contralateral hemisphere.

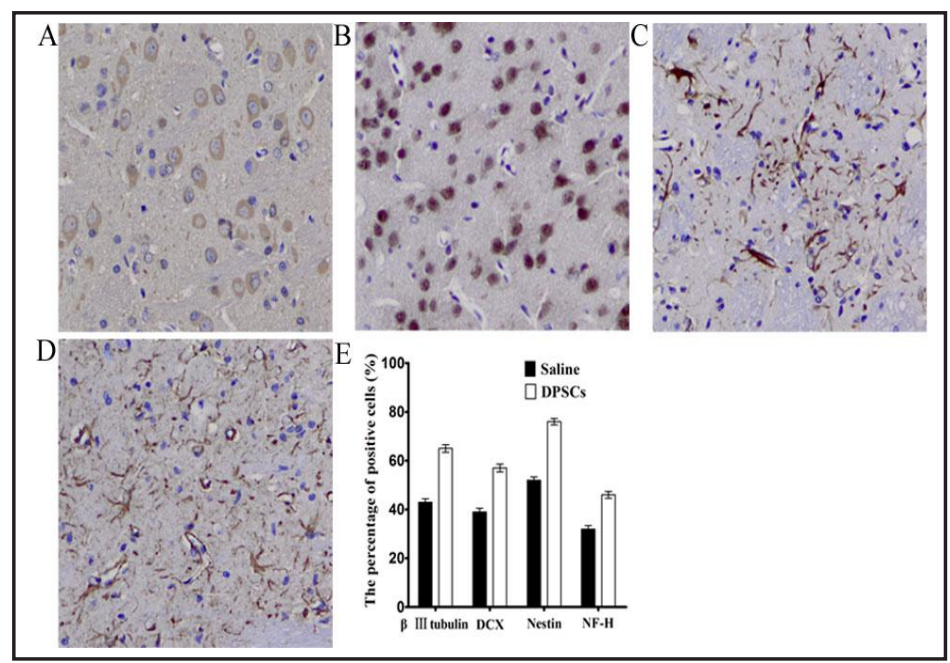

Fig. 5. The expression of neural specific markers $\beta$ III tubulin, DCX, Nestin and NF-H is up-regulated in DPSCs group compared with saline group by immunohistochemistry. 


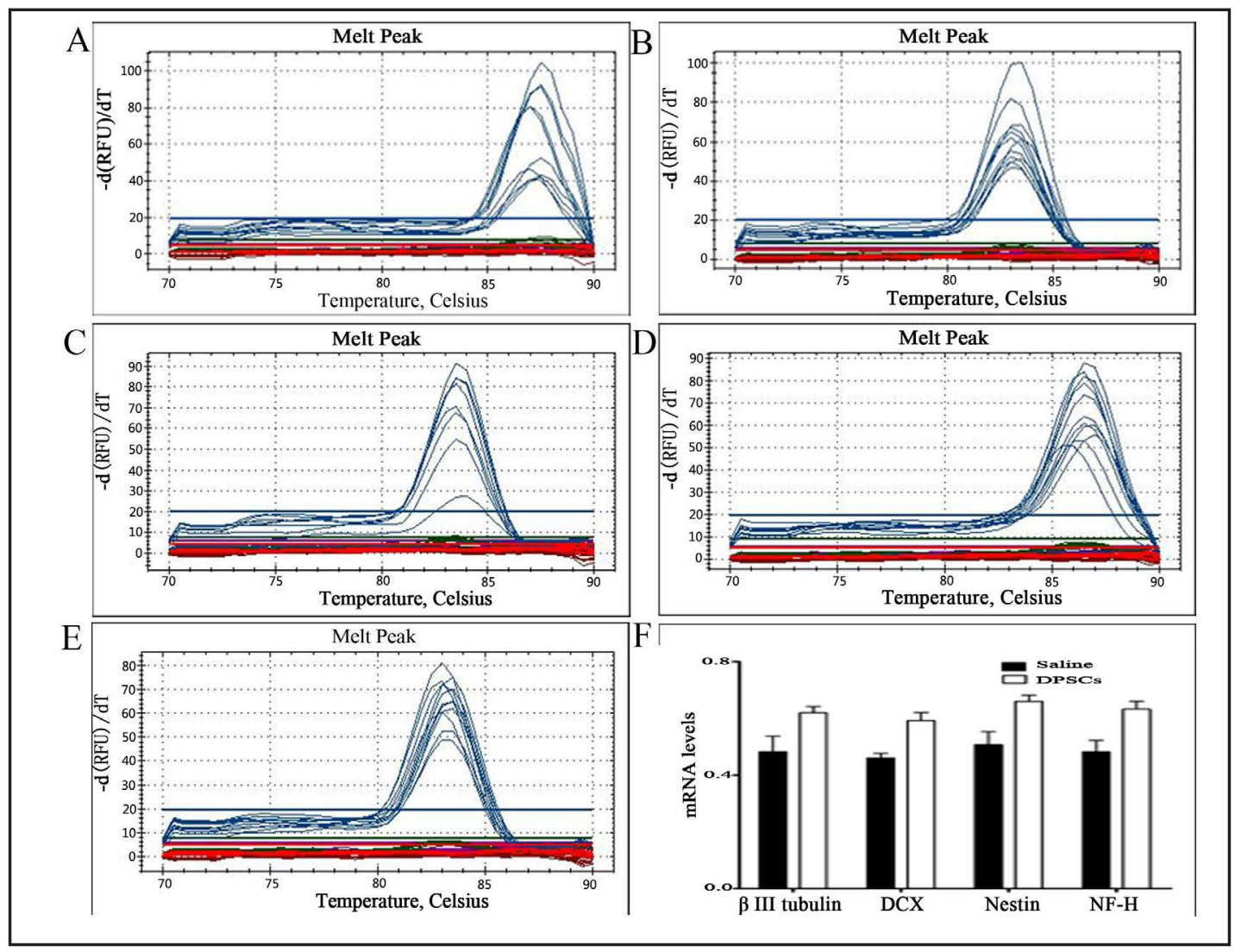

Fig. 6. The gene expression of neural specific markers is up-regulated in DPSCs group compared with saline group by RT-PCR.

intra-arterial, intrastriatal and intraventricular injection. Intravenous administration is safe, optimal and effective in present study and is suitable for clinical application. Transplanted DPSCs are identified with lipophilic green fluorescence dye PKH 67, and at 4 week posttransplant they express neural cell markers $\beta$ III tubulin, DCX, Nestin \& NF-H and are colocalized with DAPI in ischemic brain regions. Gene level analysis of the differentiating DPSCs was verified by Real-time PCR analysis.

A large number of PKH 67 labeled cells mainly gathered in the boundary of brain ischemic areas. This distribution pattern suggests that transplanted DPSCs could traverse the blood-brain barrier without the use of a permeabilizer. DPSCs survived, proliferated and migrated towards the injured regions and did not induce teratomas formation. Noninvasive tracing using green fluorescent dye PKH 67 provides an accurate and practical method to track grafted cells in vivo, which can be widely used in the research of cell transplantation therapy.

The mechanism underlying the migration of intravenously transplanted DPSCs to the ischemic lesions remains unclear. Several studies have reported that stem cells mobilization mechanism may involve cytokines, chemokines, and growth factors released at the injured site and hypoxia environment [20]. Stromal cell-derived factor 1 (SDF-1), which is a strong chemoattractant, is widely expressed by a variety of tissues such as the bone marrow, heart, liver, lung, lymph nodes, kidney, and brain [21]. SDF-1 and its receptor CXCR4 play vital roles in the homing of stem cells [22]. Our results illustrated that the groups which received DPSCs had a decreased infarct volume compared with the sham group. Another possible hypothesis is that interaction of DPSCs with the host brain may activate endogenous stem cell to proliferate and self-repair. In addition, DPSCs may attenuate stroke-induced inflammation and improve microenvironment in subcortical regions of the ischemic brains, protecting the 


\section{Cellular Physiology Cell Physiol Biochem 2018;45:258-266 \begin{tabular}{l|l|l} 
DOI: 10.1159/000486772 & $\begin{array}{l}\text { C } 2018 \text { The Author(s). Published by S. Karger AG, Basel } \\
\text { www.karger.com/cpb }\end{array}$
\end{tabular}}

Zhang et al.: Dental Pulp Stem Cells Express Neural Markers in Cerebral Ischemia Model

brains against ischemia. There are numerous preclinical studies using DPSCs transplantation needed to be investigated for neurological diseases. This beneficial treatment may become an important regenerative therapeutic strategy for clinical stroke patients in the future.

\section{Acknowledgements}

This work was supported by Yu Weihan Fund for Distinguished Young Scholars of Harbin Medical University.

\section{Disclosure Statement}

The authors have nothing to disclose.

\section{References}

1 Feigin VL, Forouzanfar MH, Krishnamurthi R, Mensah GA, Connor M, Bennett DA, Moran AE, Sacco RL, Anderson L, Truelsen T, O’Donnell M, Venketasubramanian N, Barker-Collo S, Lawes CM, Wang W, Shinohara Y, Witt E, Ezzati M, Naghavi M, Murray C, Global Burden of Diseases I, Risk Factors S, the GBDSEG: Global and regional burden of stroke during 1990-2010: findings from the Global Burden of Disease Study 2010. Lancet 2014;383:245-254.

2 Ibarretxe G, Crende 0, Aurrekoetxea M, Garcia-Murga V, Etxaniz J, Unda F: Neural crest stem cells from dental tissues: a new hope for dental and neural regeneration. Stem Cells Int 2012;2012:103503.

3 Alge DL, Zhou D, Adams LL, Wyss BK, Shadday MD, Woods EJ, Gabriel Chu TM, Goebel WS: Donor-matched comparison of dental pulp stem cells and bone marrow-derived mesenchymal stem cells in a rat model. J Tissue Eng Regen Med 2010;4:73-81.

4 Zhang W, Walboomers XF, Shi S, Fan M, Jansen JA: Multilineage differentiation potential of stem cells derived from human dental pulp after cryopreservation. Tissue Eng 2006;12:2813-2823.

5 Woods EJ, Perry BC, Hockema JJ, Larson L, Zhou D, Goebel WS: Optimized cryopreservation method for human dental pulp-derived stem cells and their tissues of origin for banking and clinical use. Cryobiology 2009;59:150-157.

6 Mead B, Logan A, Berry M, Leadbeater W, Scheven BA: Paracrine-mediated neuroprotection and neuritogenesis of axotomised retinal ganglion cells by human dental pulp stem cells: comparison with human bone marrow and adipose-derived mesenchymal stem cells. PLoS One 2014;9:e109305.

$7 \quad$ Nosrat IV, Widenfalk J, Olson L, Nosrat CA: Dental pulp cells produce neurotrophic factors, interact with trigeminal neurons in vitro, and rescue motoneurons after spinal cord injury. Dev Biol 2001;238:120-132.

8 Nosrat IV, Smith CA, Mullally P, Olson L, Nosrat CA: Dental pulp cells provide neurotrophic support for dopaminergic neurons and differentiate into neurons in vitro; implications for tissue engineering and repair in the nervous system. Eur J Neurosci 2004;19:2388-2398.

9 Winderlich JN, Kremer KL, Koblar SA: Adult human dental pulp stem cells promote blood-brain barrier permeability through vascular endothelial growth factor-a expression. J Cereb Blood Flow Metab 2016;36:1087-1097.

10 Apel C, Forlenza OV, de Paula VJ, Talib LL, Denecke B, Eduardo CP, Gattaz WF: The neuroprotective effect of dental pulp cells in models of Alzheimer's and Parkinson's disease. J Neural Transm (Vienna) 2009;116:7178.

11 Mead B, Logan A, Berry M, Leadbeater W, Scheven BA: Intravitreally transplanted dental pulp stem cells promote neuroprotection and axon regeneration of retinal ganglion cells after optic nerve injury. Invest Ophthalmol Vis Sci 2013;54:7544-7556.

12 Sasaki R, Aoki S, Yamato M, Uchiyama H, Wada K, Okano T, Ogiuchi H: Tubulation with dental pulp cells promotes facial nerve regeneration in rats. Tissue Eng Part A 2008;14:1141-1147.

13 Gao L, Ji X, Song J, Liu P, Yan F, Gong W, Dang S, Luo Y: Puerarin protects against ischemic brain injury in a rat model of transient focal ischemia. Neurol Res 2009;31:402-406. 


\section{Cellular Physiology Cell Physiol Biochem 2018;45:258-266

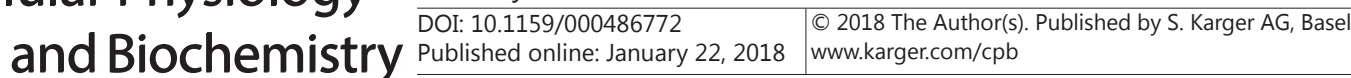 \\ Zhang et al.: Dental Pulp Stem Cells Express Neural Markers in Cerebral Ischemia Model}

14 Ostrowski RP, Colohan AR, Zhang JH: Mechanisms of hyperbaric oxygen-induced neuroprotection in a rat model of subarachnoid hemorrhage. J Cereb Blood Flow Metab 2005;25:554-571.

15 Katsetos CD, Legido A, Perentes E, Mork SJ: Class III beta-tubulin isotype: a key cytoskeletal protein at the crossroads of developmental neurobiology and tumor neuropathology. J Child Neurol 2003;18:851-866; discussion 867.

16 Tischfield MA, Engle EC: Distinct alpha- and beta-tubulin isotypes are required for the positioning, differentiation and survival of neurons: new support for the 'multi-tubulin' hypothesis. Biosci Rep 2010;30:319-330.

17 Brown JP, Couillard-Despres S, Cooper-Kuhn CM, Winkler J, Aigner L, Kuhn HG: Transient expression of doublecortin during adult neurogenesis. J Comp Neurol 2003;467:1-10.

18 Couillard-Despres S, Winner B, Schaubeck S, Aigner R, Vroemen M, Weidner N, Bogdahn U, Winkler J, Kuhn HG, Aigner L: Doublecortin expression levels in adult brain reflect neurogenesis. Eur J Neurosci 2005;21:114.

19 Michalczyk K, Ziman M: Nestin structure and predicted function in cellular cytoskeletal organisation. Histol Histopathol 2005;20:665-671.

20 Naaldijk Y, Johnson AA, Ishak S, Meisel HJ, Hohaus C, Stolzing A: Migrational changes of mesenchymal stem cells in response to cytokines, growth factors, hypoxia, and aging. Exp Cell Res 2015;338:97-104.

21 Wurth R, Bajetto A, Harrison JK, Barbieri F, Florio T: CXCL12 modulation of CXCR4 and CXCR7 activity in human glioblastoma stem-like cells and regulation of the tumor microenvironment. Front Cell Neurosci 2014;8:144.

22 Yu Y, Wu RX, Gao LN, Xia Y, Tang HN, Chen FM: Stromal cell-derived factor-1-directed bone marrow mesenchymal stem cell migration in response to inflammatory and/or hypoxic stimuli. Cell Adh Migr 2016;10:342-359. 